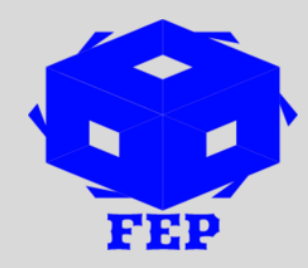

\title{
BUBBLE PREDICTION AND COMPARATIVE ANALYSIS OF EMERGING AND MATURE MARKETS
}

\author{
Hyang Lee ${ }^{1}$, Jungyoung Park ${ }^{2}$
}

${ }^{1}$ Hongik University, Seoul, South Korea

*Corresponding Author: Hyang Lee

Article Received: 08-10-19
Accepted: 28-12-19

Published: $10-01-20$

Licensing Details: Author retains the right of this article. The article is distributed under the terms of the Creative Commons Attribution-Non Commercial 4.0 License (http://www.creativecommons.org/licences/by-nc/4.0/) which permits non-commercial use, reproduction and distribution of the work without further permission provided the original work is attributed as specified on the Journal open access page.

\begin{abstract}
By analyzing the financial bubbles, it can be observed that every bubble burst causes financial turmoil and severe economic recession. The paper utilize the technical analysis indicators for providing warning conditions for predicting the stock market bubbles. The significance of the technical analysis indicators are that they can provide early warning system for financial crisis and can help in avoiding such problems. We applied the early warning technical indicators to the stock market of US, South Korea, Brazil, China, Germany, and Japan for the period of 1995 to 2018. We also made comparison of the bubble warning conditions of emerging markets and the mature markets. The standard bubble warning conditions include $\mathrm{K}$ value 90 , Bias $10 \%$, and RSI value of 90. Empirical results shows that mature market shows less degree of volatility and lowering the warning baseline can improve the accuracy of bubble predictions. Furthermore, results shows that mature markets bursting time is about 6 months while in emerging market, the time is reduced to only 3 months. These results also indicate that mature market has good antirisk ability compare to the emerging markets.
\end{abstract}

Keywords: Technical Indicator, Bias, Stock Market Bubbles

\section{INTRODUCTION}

The first tulip financial bubble was occurred in Netherland in 1637 almost 380 years ago. There are several financial bubbles which emerged with the passage of time. Academics put 
greater deal of efforts to identify the predictors of financial bubbles for reducing its negative effects. In this paper, we provide technical indicators which can be used to predict financial bubbles. The expectations are that we can use these indicators for financial bubble prediction. The early warning conditions of technical analysis are used for predicting the stock market bubbles in mature markets and emerging markets for identification of differences as well.

\section{LITERATURE REVIEW}

In financial academic field, the financial bubble related research is a hot topic. One significant theory in this field is the rational bubble theory which states that on the market efficiency hypothesis, participants are rational and in situation of limited trading, there will be no asset price bubbles. Santos and Woodford (1997) states that asset price and the present value of the divided represented by the asset are equal and the asset price bubble is unlikely to occur but the conclusion is based on several assumptions. In actual economic life, the assumption that investors have rational prediction is quite unrealistic. Hence, the limitation of the rational bubble theory is that it cannot reasonably explains many bubbles in financial markets. Alternatively, the irrational bubble theory is produced which explain the bubble phenomenon from irrational factors. The theory states that change and complexity of the real financial market is product of non-linear affection. From the irrationality perspective, the theory states that individual psychology of trades and causes of bubble are microscopic perspective. DSSW model also known as noise trader model produced by DeLong (1990) shows that unpredictability of noise trader beliefs brought risks to asset prices. Furthermore, the risk aversion attitude of arbitrageurs limits their ability to correct mispricing thus enabling stocks. Hence, there is continuous diversion from underlying value to the market price. The BSV model known as investor sentiment model by Barberis, et al., (1998) uses the public information to predict future cash flows leading to systematic errors because of varying emotions and causing the stock price to deviate from the basic value and leading to the bubbles.

Based on nonlinear dynamic theory and behavioral finance theory, several scholars have provided in-depth analysis on financial bubbles. The LPPL model also known as Log Periodic Power Law model is the most representative of these models in the category of nonlinear dynamic theory. A study by Johansen and Sornette (1996) compared the stock market crash with the physical material fracture. It studied the US bubble of 1987 using the first order logarithmic period power law model and the bubble in the process of collapsing fits well with the logarithmic period oscillations. This model is studied by Johansen and 
Sornette (1996) for understanding the 21 bubbles in different markets and found it reliable. In regard to the behavioral finance theory, feedback theory is used by Shiller (2001) for explaining the process of generating, amplifying, and destroying of stock market bubbles. The asset price bubble is found to be expanded because of past prices which gave investors the expectations and confidence for stock.

When we review the financial bubble theory, it is clear that investor irrationality assumptions are closer to the realistic securities market. Thus, behavioral finance plays key role in bubble related research. The beauty of behavioral finance is that it integrates the psychology and finance field and uses different principles to explain individual behavior. The technical analysis is used for understanding the market behavior which includes and digest everything. It can be used for analyzing and predicting quantitatively the price. Based on periodicity of trends, the technical analysis can be used for judging market and making decisions. There are three major assumptions of technical analysis including history repeating itself, certain trend for stock prices, and market include all information. From behavioral finance perspective, these three assumptions are studied by Yang, et al., (2010). Overall, the technical analysis can be used effectively in securities market. In this study, we attempt to use the technical analysis for predicting the stock market bubbles.

As far as literature is concerned, so most literature used for testing the efficiency or weak efficiency market hypothesis. For example, study by Shi (2013) is used for conducting technical analysis in Mainland China, Taiwan, and Hong Kong. In present study, we used seven technical indicators for testing the effectiveness of technical analysis in the Asian 1997 Asian financial turmoil, the 2000 Internet bubble and the 2008 Lehman storm. According to several academic community, the asset pricing model is used for entry point for detecting the stock market bubbles. At the core of this study, the aim is to investigate the intrinsic value of the stock and then judging the gap between the stock price and the intrinsic value for analyzing the size of the bubble. For estimating the intrinsic value, there are various methods. For example, Campbell and Shiller (1998) utilized the divided price ratio and price earning ratios for forecasting the variables for the stock market. Cointegration test is utilized by Engle and Granger (1987). Euler equation test is utilized by West (1998). Zhou (1998) utilized the dynamic autoregressive method; while, price earning comparison is utilized by the White (2000). In Wu, et al., (2004) study, the divided payout ratio for China stock market was zero. In this study, we used the overbought status of technical indicators and the excessive bias as the bubble warning conditions to predict the bubble and analyze the size of the bubble. 


\section{RESEARCH METHODOLOGY}

The period utilized is from $1^{\text {st }}$ January 1995 to $31^{\text {st }}$ December 2018 for obtaining the weekly frequency index of six countries. The six indexes are Korea composite index, Brazil Sao Paulo Index, China Shanghai Composite Index, Germany DAX index, Japan Nikkei 225 index, and American Dow Jones Index. We used three technical indicators for testing whether the current market is in a state of overheating and predicting if there is a bubble in the stock price. We also examined the future trend of stock prices by utilizing the 200-day moving average as proposed by Granville (1960). There is representation of first point of purchase as $1 \mathrm{~S}$ represents the first selling point and we can see the bubble point of overheating in the market is a point like $4 \mathrm{~S}$. At this time, the $4 \mathrm{~S}$ indicate that stock price deviates from the 200MA largely and will be leading to a large drop in stock prices.

A Taiwanese investment expert named as $\mathrm{Hu}$ (2009) introduced the gravity line of the stock market in his book. He shows that the track line is based on three lines including the central track consist of $51 \mathrm{MA}$, the upper track consist of $10 \%$ of central track, and the lower track consist of $-10 \%$ of the central track. Accordingly, the stock prices rises to the upper track referring to $10 \%$ away of stock prices from its central axis. It can be considered as a selling point and the principle of gravity will pull the stock price back to the normal range on the contrary, when the stock price falls to the lower track, it is a buying point and the principle of gravity will make the stock price rebound. The study is based on the track line indicators using weekly data instead of daily data. We set the central track to 13 weeks MA (quarter line), and the upper track (positive bias) changes from $+5 \%$ to $+15 \%$ which is a total of 11 upper track lines.

On this basis, this paper adds common technical indicators including the relative strength index, and the stochastics oscillator for capturing the track line and the crisis warning of the bubble more accurately. In technical analysis, these two technical indicators are the most commonly used by investors and their value range from 0 to 100 . Their operations are as follows; from 0 to 20 are oversold areas and refers to good time for buying; 80 to 100 are overbought areas and refers to good time for selling. The method of research uses the RSI and $\mathrm{K}$ both greater than 90 as one of the bubble warning conditions. In summary, the standard bubble warning conditions are $\mathrm{K}$ value of $\mathrm{KD}$ and RSI of greater than 90 . Furthermore, as the $10 \%$ upper track is touched by the stock price, it shows bias is almost $10 \%$. The technical analysis also suggest that volatilities of global markets are not the same and varies based on the different market structural characteristics. For instance, the volatility 
of mature market such as United States and Europe is different from emerging markets. Therefore, we cannot utilize the same standard bubble warning conditions for all six countries under investigation. Hence, it was required to adjust the warning conditions for different countries.

Firstly, drawing bubble warning points in red that satisfies the warning conditions (RSI $>90$, $\mathrm{K}>90$, deviation rate $>10 \%$ ) on the weekly stock price chart to observe the distribution of bubble warning points in six countries. We calculated the maximum drop of each bubble warning point within the next 3 months and judge the applicability of standard bubble warning conditions to the country and then adjust the overhead indicators accordingly. After doing that, we kept the RSI value and the $\mathrm{K}$ value unchanged and the bias gradually increased from $5 \%$ to $15 \%$. The bubble warning point is obtained under changing conditions and then calculated maximum drop in the stock price within 1 month, 2 months, 6 months after the bubble warning point appear.

\section{EMPIRICAL RESULTS}

In our standard bubble warning conditions, bias is greater than $10 \%$ and K and RSI are greater than 90. The condition is utilized for capturing the bubble warning points of the selected stock markets. In situation where the stock price index is falling more than $5 \%$ within the observation interval after the bubble warning point appears, it indicating that the bubble bursting and the bubble warning point is an accurate warning. From the accuracy perspective, the RSI value and the K value along with bias are appropriately adjusted to seek the best bubble warning conditions for each country.

\section{America (DJI)}

For American context, the stock price index is represented by solid line and the dots distributed on the solid line represents the bubble warning point. At this particular occasion, the $\mathrm{K}$ and the RSI are both greater than 90 and the Bias is greater than $10 \%$. On right axis, maximum drop in the figure is represented along with the corresponding bubble warning point within 3 months. The figure shows only single warning point being captured under the standard bubble warning condition. The value of the $\mathrm{X}$ vertical line of this warning point is about 5 which indicate that there is maximum drop of this bubble warning point is about $5 \%$ within the next 3 months.

In the observation time which changing from 1 month to 3 months in the vertical direction, whereas, the second number is the representative bias changing from $5 \%$ to $15 \%$ in the 
horizontal direction; and the third number is the bubble warning points. The three columns in the small histogram shows the drop distribution of the bubble warning point in the observation interval. The dropped bubble shown is less than $5 \%$ to $10 \%$ and above $10 \%$. On left, there are small figures of $0,0.5$, and 1 which indicate that there is 0 to 1005 drop distribution. The results also shows that in situation where the bubble warning conditions are relaxed, only few captured bubble warning points will be bursting within next 3 months. We attempted to extend the observation interval for 6 months as provided in the figure. The histogram indicates that in situation when bias is $8 \%$, along with corresponding RSI and $\mathrm{K}$ value of 85 , the eight bubble warning points captured will all burst in the 6 months. Hence, for the stock market of US, the bubble warning points are taking longer time to burst and optimal bubble warning condition is k value 85 , bias $8 \%$, and RSI value of 85 .

\section{Japan (N225)}

The figure for Japan stock market shows that utilizing the bubble warning conditions, there are 12 bubble warning points in the Japanese stock market and most bubble warning points have not broken within 3 months with maximum drop of less than $5 \%$. If we increase the $\mathrm{K}$ value limit and the RSI value, it will bring reduction in the number of bubble warning points and lack practical reference.

RSI value will greatly reduces the number of bubble warning points and lack practical references. Hence, in this study, we attempted to bring reduction in the K value and the RSI value to 85 and observe the bursting of the bubble warning point under different bias values. Further analysis shows that when the $\mathrm{K}$ value and the RSI values are reduced to 85 and bias is about $14 \%$, the two bubble warning points captured will burst within 1 month. However, due to the small number of warning points being captured, the reference value for practice is relatively lower. Hence, we extended the observation time to 6 months and dropped distribution of bubble warning points as show in figure. In situation of observation time of 6 months along with $11 \%$ bias, there are 17 bubble warning points captured which all bursting and dropping greater than $10 \%$. Hence, we can conclude that for the Japanese market, the bubble warning points will be taking longer time for bursting and optimal bubble warning condition is RSI value and $\mathrm{K}$ value of 85 along with bias of $11 \%$.

\section{Germany (DAX)}

The figure for Germany stock market showing its 12 bubble warning points under the standard bubble warning condition. Most of the warning are not broken during last 3 months 
with maximum drop of less than $5 \%$ so we can conclude that prediction effect is not accurate enough. For German market, the market can be considered quite mature, hence, the warning conditions are quite strict for it. Hence, we attempted to bring reduction in the RSI value to 85 and $\mathrm{K}$ value to 85 with drop distribution of the bubble warning points captured under different bias values. The analysis shows this fact that in situation when the RSI and K values are lowed to 85 , the bubble prediction accuracy under varying bias values cannot reach $100 \%$ within 3 months as the first column in the small histogram not disappeared so the observation time is extended to 6 months and the bubble point drop distribution is show in figure. It indicate that in situation of observation time extending for 6 months, the bias remains $8 \%$, and there are almost 30 bubble warning points captured which are all bursting and drop is greater than $10 \%$. Hence for Germany stock market, the bubble warning points are taking longer time to burst and its optimal bubble warning condition is RSI value of $85, \mathrm{~K}$ value of 85 , and bias of $8 \%$.

\section{China (SHI)}

The figure for China shows that there are total of 35 bubble warning points captured under the standard bubble warning conditions and in the interval between of 2006 to 2007 and between 2015 to 2016, several bubbles maximum drops were less than 5\%. This is because Chinese stock market is a bull market at that time thus using 90 as the limits for the $\mathrm{K}$ value and the RSI value is not enough to measure, hence we increasing the value to 95 to observe the maximum drop distribution of bubble warning points under this condition.

that Chinese stock market was the bull market at that time, thus, using 90 as the limits for the $\mathrm{K}$ value and the RSI value is not enough to measure, therefore we increase the value to 95 to observe the maximum drop distribution of bubble warning points under this condition. Furthermore it shows that the $\mathrm{k}$ value and the RSI value are increased to 95 while bias reaches up to $5 \%$ which accurately capturing the bubble warning point which means in situation when bubble warning point appears under the warning conditions, the stock price index will fall by more than $5 \%$ in the upcoming two months. For Chinese stock market, the bubble burst will occur in a short period of time after the bubble warning point appears. The optimal bubble warning condition is RSI value of $95, \mathrm{~K}$ value of 95 , and bias of $5 \%$.

It can be seen from the small graph $(2,5,5)$ in that the $\mathrm{K}$ value and the RSI value are increased to 95 , and the Bias is 5\%, which accurately capture the bubble warning point, that is, when bubble warning points appear under the warning conditions, the stock price index will fall by more than $5 \%$ in the next two months, it is necessary to be alert to the stock 
market. Therefore, for the Chinese stock market, the bubble burst will occur in a short period of time after the bubble warning point appears. The optimal bubble warning condition is $\mathrm{K}$ value 95, RSI value 95, and Bias 5\%.

\section{Brazil (IBOVESPA)}

The figure for Brazilian stock market shows that under the standard bubble warning conditions showed 27 bubble warning points. However, several warning points have not broken within the next 3 months. Furthermore, the efficiency of these bubble warning is also found to be lower. As far as Brazil is concerned, so it can be categorized as an emerging market with higher volatility. Therefore, we attempted to enhance the $\mathrm{k}$ value and the RSI value to 95 to observe the distribution of the maximum drop in the bubble warning point under different bias values. Additionally, it shows that in situation where $\mathrm{k}$ value reached to 95, the RSI value was also 95 and the bias is about 5\%, and the 3 bubble warning points captured which will be bursting within the next month. Hence, we can conclude that for the Brazilian stock market, the bubble burst can occurs in a shorter period of time after the bubble appears. For Brazil, the optimal bubble warning conditions were RSI value of 95, K value of 95 , and bias of $5 \%$.

\section{Korea (KS11)}

The figure for Korea shows that for south Korean stock market, 9 bubble warning points were captured under the standard bubble warning conditions. Out of these, maximum drop of all bubble warning points in three months exceeded 5\%. Hence, the standard bubble warning conditions with bias of $10 \%$, RSI of 90 , and K of 90 are suitably applicable to bubble predictions of the south Korean stock market. On this basis, we observed that drop distribution of the bubble warning points captured by different bias values seeking the best bubble warning conditions.

The further analysis shows that in situation where bias reaches to $5 \%, 17$ bubble warning points were captured having maximum drop of about 5 in the following 3 months observation time. Furthermore, more than $50 \%$ warning points dropped more than $10 \%$. Hence for South Korean stock market, the bubble bursts in comparatively shorter time period after bubble appears. For South Korea, the optimal bubble warning conditions are bias of 5\%, RSI value of 90 , and $\mathrm{K}$ value of 90 . 


\section{CONCLUSION}

The conclusion of the study is that from the observation time, the bubbles captured in mature markets takes about 6 months to burst; whereas, the bubbles captured in emerging markets burst up rather quickly in about 3 months' time period. Thus, we conclude that emerging markets are sensitive to bubbles and weaker in risk resistance. In situation where bubble warning points appear, it shows that in emerging market, these bubble are about to burst which shows that bubble warning mechanism is more suitable for the emerging markets. With regard to the optimal bubble warning conditions, the emerging and mature market have varying volatilities and their optimal bubble warning conditions need to be adjusted according to the volatility which makes it suitable for its own market conditions. While observing the optimal bubble warning conditions, the adjusted interval of RSI value and $\mathrm{K}$ value is 5 from 90 to 95 .

\section{References}

Barberis, N., Shleifer, A., \& Vishny, R. (1998). A model of investor sentiment. Journal of Financial Economics, 49, 307-343.

Campbell, J.Y., \& Shiller, R.J. (1998). Valuation ratios and the long-run stock market outlook. Journal of Portfolio Management, 24(2), 11-26.

DeLong J. B., Shleifer, A., Summers, L.H. (1990). Noise trader risk in financial markets. The Journal of Political Economy, 98(4), 703-738.

Engle, R.F., \& Granger, C.W.J. (1987). Co-integration and error correction: representation, estimation, and testing. Econometrica, 55(2), 251-276.

Granville, J.E. (1976). Granville's new strategy of daily stock market timing for maximum profit. Prentice-Hall.

Hu, L.Y. (2009). 100 Stock Investment Strategies by Liyang Hu. Taiwan: Economic Daily.

Johansen, A., Sornette, D., Bouchaud, J.P. (1996). Stock market crashes, Precursors and Replicas. Journal of Physical Finance, 6, 167-175.

Johansen, A., \& Sornette, D. (2001). Log-periodic power law bubbles in Latin-American and Asian markets and correlated anti-bubbles in Western stock markets: An empirical study. International Journal of Theoretical and Applied Finance, 4(6), 853-920.

Mi, N. (2015). The effectiveness of technical analysis of securities market in terms of behavioral finance. Modern Business, 14, 235-237.

Pan, G.L. (2000). A study of the stock market bubble. Journal of Financial Research, 7, 7179.

Santos, M. S., \& Woodford, M. (1997). Rational asset pricing bubbles. Econometrica, 65(1), $19-58$.

Shi, D.G. (2013). The applications of the stock markets of Taiwan, Hong Kong and China: the case of global financial crisis (Unpublished master's thesis), National Yunlin University of Science and Technology, Taiwan. 
West, K.D. (1988). Bubbles, fads and stock price volatility tests: a partial evaluation. Journal of Finance, 43(3), 639-655.

$\mathrm{Wu}$, S.L. (2004). Formulation and measurement of stock market bubble. Finance \& Economics, 4, 6-11.

White, C.B. (2000). What P/E will the U.S. stock market support? Financial Analysts Journal, 56(6), 30-38.

Yang, C.L., \& Liu, X.B. (2010). The effectiveness of technical analysis on the basis of behavioral finance. Times Finance, 3, 24-26.

Zhou, A.M. (1998). The stock market bubble and its test methods. Economic Science, 5, 4449. 